\title{
THIẾT KẾ VÀ THI CÔNG HỆ THỐNG GIÁM SÁT CHẤT LỰ̛̣G NƯớC THỜI GIAN THỰC NÛ̂II THỦY SẢN NƯỚC Lợ LỒNG BÈ
}

\author{
LÊ NGOQC TRÂN \\ Khoa Công nghệ Co khí, Truờng Đại học Công nghiệp Thành phố Hồ Chí Minh; \\ lengoctran@iuh.edu.vn
}

Tóm tắt. Bài báo này trình bày quá trình thiết kế và thi công một hệ thống tự động đo và giám sát các thông số chất lượng nước nuôi cá lồng bè thời gian thực trên sông Chà Và. Hệ thống giúp các hộ nuôi cá bè phát hiện những thay đổi bất thường của thông số nước thông qua tin nhắn SMS, để có giải pháp kịp thời tránh tình trạng cá chết. Hệ thống có chức năng lưu trữ dữ liệu đo qua webserver, giúp Chi cục Thủy sản tỉnh Bà Rịa- Vũng Tàu giám sát và quản lý nuôi cá lồng trên sông Chà Và tốt hơn. Hệ thống gồm 03 phần: cảm biến, vi điều khiển và Raspberry Pi (web-server). Các cảm biến không đặt trực tiếp trong môi trường nước mặn cần đo mà được ngâm trong két nước sạch, khi đến chu kỳ đo hệ thống sẽ tự động xả nước sạch và bơm nước mặn vào két đo, sau khi kết thúc quá trình đo hệ thống sẽ truyền dữ liệu lên Webserver thông qua GSM/GPRS và gửi tin nhắn SMS nếu có thông số vượt ngưỡng, các cảm biến sau đó được tự động rửa và ngâm trong nước ngọt đảm bảo tuổi thọ và độ chính xác cho cảm biến, thời gian chu kỳ hiệu chuẩn kéo dài. Bên cạnh đó, Chi cục thủy sản có thể truy cập vào cơ sở dữ liệu để đánh giá môi trường nuôi một cách thuận lợi. Đây là bước khởi đầu để làm nền tảng cho việc ứng dụng công nghệ cao trong nuôi thủy sản lồng bè trên sông Chà Và tỉnh Bà Rịa - Vũng Tàu.

\section{DESIGN AND IMPLEMENTATION OF A REAL-TIME WATER QUALITY MONITORING SYSTEM FOR BRACKISH WATER CAGE CULTURE}

\begin{abstract}
This paper presents the designing and implementation for an automatic real time measurement and monitoring system of water quality parameters in brackish cage culture on Cha Va river. This system helps fish farmers to detect abnormal changes in water parameters via SMS messages, to have timely solutions to avoid dead fish. The system has a function for storing measurement data via webserver, helping the Fisheries Sub-Department of Ba Ria-Vung Tau province improves the monitoring and managerment cage culture on Cha Va river. The system including of sensors, microprocessor and webserver (Raspberry pi). The sensors are not placed directly in the sea water to be measured but immersed in a fresh water tank. Beginning of a measurement cycle, the tank automatically discharge fresh water and pump salt water in to the sensor tank for measurement. After measurement process is finished, the system will transmit data to webserver via GSM/GPRS or send SMS to owner if any water parameter exceed the thresholds. The sensors are then automatically washed and soaked in fresh water to ensure sensor life and accuracy and sensor calibration cycle time is extended. In addition, the Sub-Department of Fisheries can access the database to assess the aquaculture environment reality. This is the first step to lay the foundation for high-tech application in cages and aquaculture in Cha Va River, Ba Ria - Vung Tau Province.
\end{abstract}

Keywords. brackish cage culture, brackish water quality parameters, water quality sensors, microprocessor, water quality measurement and monitoring, GSM/GPRS

\section{1 ĐặT VẤN Đề}

Nuôi trồng thủy sản là một ngành phát triển nhanh vì nhu cầu thực phẩm cá và hải sản tăng mạnh trên toàn thế giới [1]. Theo thống kê [2] nguồn thực phẩm hải sản chiếm $46 \%$ tổng nguồn cung cấp thực phẩm trên toàn thế giới, do đó nuôi cá lồng ngày càng trở nên quan trọng trên toàn thế giới do nhu cầu protein cá ngày căng tăng cũng như do nguồn cung cấp ngày càng cạn kiệt do bị đình trệ từ đánh bắt tự nhiên [3]. Một khi đánh bắt thủy sản trong tự nhiên đã cạn kiệt thì ngành chăn nuôi những loài này đang ngày càng phát triển và nở rộ hơn bao giờ hết. Cụ thể, theo thống kê của Bộ nông nghiệp và phát triển nông, ngành nuôi trồng thủy sản ở khu vực Đồng bằng sông Cửu Long thời gian qua đã có những bước phát triển vượt bậc về diện 
tích và sản lượng nuôi trồng với quy mô lớn [4]. Cụ thể, năm 2012, sản lượng thủy sản của cả vùng ước đạt hơn 2,2 triệu tấn, trong đó cá nuôi là 1,7 triệu tấn và tôm là gần 400 nghìn tấn... Ngoài ra, cũng cần có một so sánh khác là tổng sản lượng thủy sản nuôi trồng của Đông bằng sông Cửu Long chiếm khoảng 70,94\% tổng sản lượng nuôi trồng thủy sản trong cả nước, với mức tăng trưởng hằng năm là $17,8 \%$. Trong số đó, dù chưa có thống kê chính xác về việc nuôi trồng thủy sản trong ao hồ và ngoài lồng bè là bao nhiêu nhưng có thể dễ dàng nhận thấy, tỷ lệ chăn nuôi ở lồng bè là rất lớn, do diện tích mặt nước tự nhiên ở khu vực này vô cùng rộng lớn. Mặc dù nuôi cá lồng được xem là con đường để tăng sản lượng cá và tạo cơ hội việc làm cho nhiều người tuy nhiên việc mở rộng nuôi lồng không có kế hoạch sẽ gây ra những hậu quả tác động xấu đến môi trường làm mất cân bằng sinh thái, do tác động quá lớn của con người vào dòng chảy tự nhiên cũng như lượng hóa chất, thuốc chữa bệnh, thức ăn chăn nuôi khổng lồ thải ra đã có những tác động tiêu cực tới hệ sinh thái, tới những loài động thực vật khác sinh sống ở trên sông.

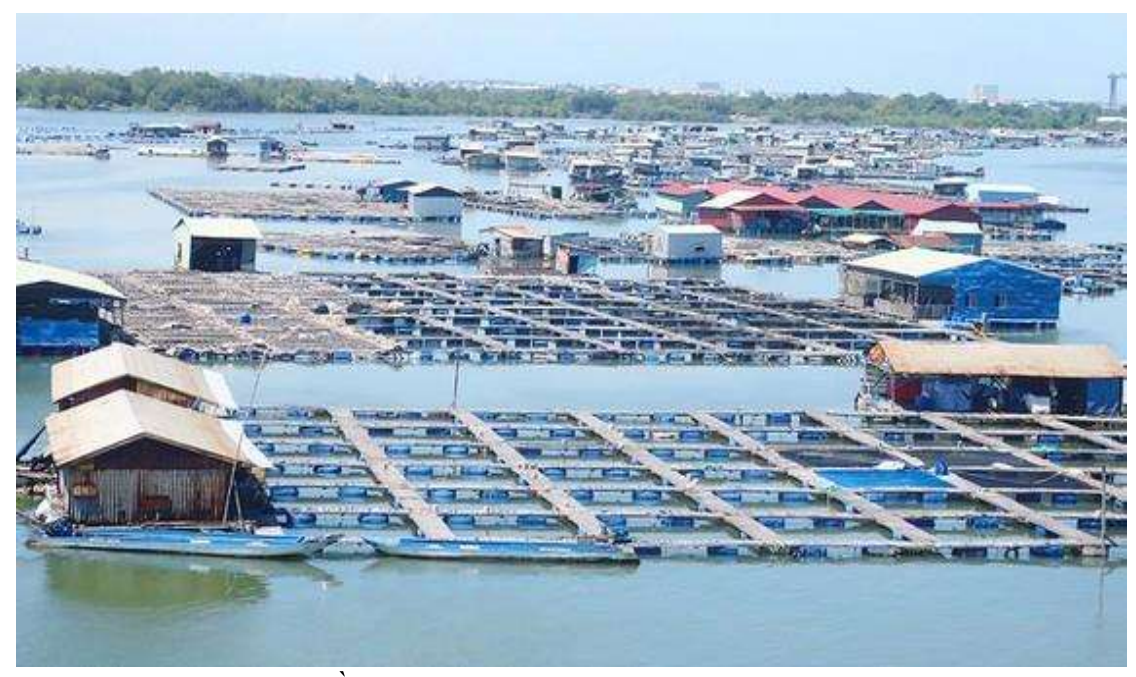

Hình 1: Nuôi cá lồng bè trên sông Chà Và tỉnh Bà Rịa- Vũng Tàu

Tại tỉnh Bà Rịa - Vũng tàu trong năm trở lại đây, việc nuôi thủy sản lồng bè (NTSLB) trên sông Chà Và (xã Long Sơn, TP Vũng Tàu) tăng lên nhanh chóng về số lượng cũng như chủng loại giúp bà con phát triển kinh tế, tuy nhiên việc phát triển không có quy hoạch cũng như chất lượng nước không đảm bảo đã gây thiệt hại rất lớn cho bà con như năm 2015, tại đây, hàng trăm tấn cá của bà con ngư dân chết hàng loạt, thiệt hại hơn 18 tỷ đồng. Cơ quan chức năng kết luận nguyên nhân chủ yếu do xả thải của các doanh nghiệp dọc sông Thị Vải. Tuy nhiên, đến năm 2016, cá lồng bè trên sông Chà Và lại tiếp tục chết với thiệt hại khoảng 37 tỷ đồng. Ngoài yếu tố ô nhiễm môi trường tích tụ, cơ quan chức năng đã chỉ ra nguyên nhân cá chết hàng loạt là thời tiết thay đổi đột ngột dẫn đến độ mặn giảm và nhất là việc NTSLB với mật độ dày đặc đã gây nên tình trạng thiếu ôxy trong nước. Hiện tại công việc đánh giá chất lượng nước nuôi thủy sản lồng bè do Chi cục Thủy sản tỉnh Bà Rịa- Vũng Tàu phụ trách, quy trình lấy mẫu và kiểm định đánh giá chất lượng nước được trình bày trong hình 2 . Việc lấy mẫu nước được thực hiện thủ công với tần suất 02 lần/ tháng, các điểm lấy mẫu ở giữa sông thời gian lấy mẫu từ 11-12 giờ trưa, di chuyển bằng ghe, rất vất vả cho người lấy mẫu, sau đó gửi mẫu đi phân tích để đánh giá chất lượng nước mất nhiều thời gian và cho kết quả không chính xác tại thời điểm lấy mẫu. Phương pháp này không hiệu quả do mất nhiều thời gian, tốn nhân công lao động, tốn chi phí lấy mẫu, chi phí phân tích mẫu nhưng kết quả không thể hiện chính xác thông số tại thời điểm đo. Do đó khi kết quả chuyển đến bà con nuôi thủy sản lồng bè bị chậm nên khi có sự cố về chất lượng nước, các chủ bè không có giải pháp kịp thời hậu quả là cá nuôi chết hàng loạt như trong thời gian qua. 


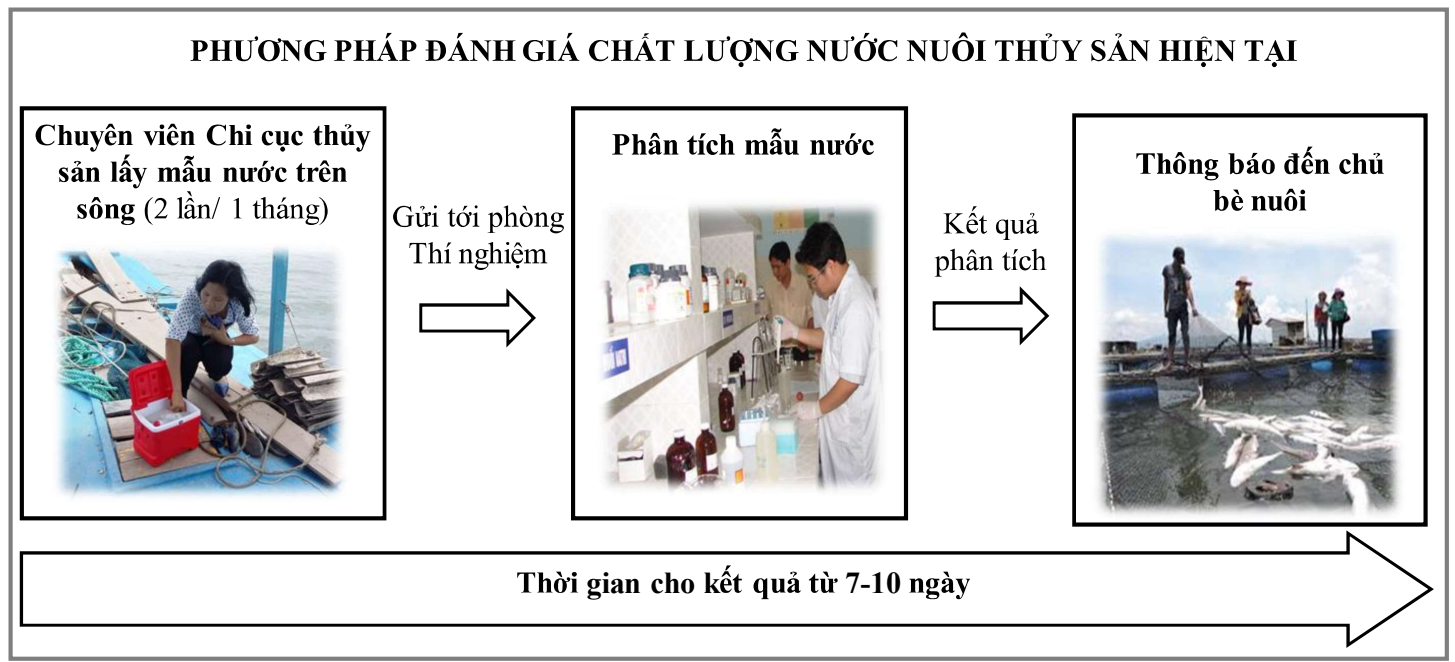

Hình 2: Phương pháp đánh giá chất lượng nước NTTS trên sông Chà Và tỉnh BRVT

Qua phân tích, đánh giá tình hình thực tế nuôi thủy sản lồng bè trên sông Chà Và cho thấy việc nghiên cứu, thiết kế, chế tạo và đưa vào ứng dụng hệ thống tự động đo, phân tích, giám sát và cảnh báo sớm chất lượng nước thử nghiệm tại các hộ dân nuôi trồng thủy sản trên sông Chà Và, tỉnh Bà Rịa - Vũng Tàu rất cấp thiết cần phải thực hiện. Giải pháp tuy là không sớm so với thế giới nhưng ở thời điểm này là rất phù hợp với tình hình nuôi trồng thủy sản trên các bè nuôi sau hàng loạt sự cố cá chết tại sông Chà Và tỉnh BRVT. Hiện nay các hệ thống quan trắc chất lượng nước nuôi thủy sản lồng bè đã phát triển mạnh mẽ và phổ biến trên thế giới, đặc biệt là các nước phát triển như Mỹ, Canada, Nhật, Anh, Trung Quốc,...Ở Việt Nam, hiện nay có một số công ty đã cho ra đời một số sản phẩm "Hệ thống giám sát môi trường nước thủy sản phục vụ nuôi tôm, cá giống tại các ao nuôi, một số sản phẩm cụ thể như: Hệ thống quan trắc môi trường nước thủy sản qua Internet E-SENSOR AQUA, xuất sú Việt Nam cảm biến nhập tì̀ Mỹ; Hệ thống giám đo và giám sát chất lượng nước nuôi trồng thủy sản Libelium (Nhập tù Tây Ban Nha); Hệ thống đo luòng và giám sát chất lượng nuôi trồng thủy sản của Công ty Cổ phần Kỹ Thuật Môi trường Việt An,... Nhìn chung các sản phẩm này giải quyết được các vấn đề tự động đo, giám sát và cảnh báo các chỉ tiêu chất lượng nước vượt ngưỡng qua thiết bị điện thoại thông minh phục vụ NTTS tại các ao nuôi liên quan đến nuôi tôm và cá giống. Một số dự án chỉ mang tính ứng dụng cụ thể qua các hợp đồng mua bán, lắp đặt thiết bị từ các cơ sở thiết kế sản xuất sản phẩm nước ngoài qua các công ty phân phối với giá thành rất cao. Do vậy với điều kiện tài chính còn hạn hẹp như hiện nay, nếu cứ tiếp tục nhập công nghệ từ nước ngoài sẽ dẫn tới việc các cơ sở sản xuất, nhất là các hộ gia đình sẽ không có đủ kinh phí để có thể mua đủ các hệ thống giám sát, điều khiển tất cả các thông số cần thiết. Ngoài ra, trong các hệ thống trên các cảm biến được nhúng thẳng trực tiếp vào môi trường nước mặn nên tuổi thọ giảm, độ chính xác không cao và phải hiệu chuẩn thường xuyên. Khắc phục những nhược điểm của các hệ thống quan trắc chất lượng nước có trên thị trường Việt Nam, trong dự án này chúng tôi sử dụng các cảm biến công nghiệp có độ chính xác cao, các cảm biến không đặt trực tiếp trong môi trường nước mặn cần đo mà được ngâm trong két nước sạch, khi đến chu kỳ đo hệ thống sẽ tự động xả nước sạch và bơm nước mặn vào két đo, sau khi kết thúc quá trình đo và truyền dữ liệu hệ thống sẽ rửa cảm biến và bơm nước sạch vào két để ngâm cảm biến, đảm bảo tuổi thọ và độ chính xác cho cảm biến, thời gian chu kỳ hiệu chuẩn kéo dài. Việc triển khai dự án "Thiết kế, chế tạo và lắp đặt hệ thống tụ động đo, phân tích, giám sát và cảnh báo sớm chất lựng nước nuôi trồng thủy sản trên sông Chà Và, tỉnh Bà Rịa - Vũng Tàu" là vô cùng quan trọng được lãnh đạo tỉnh Bà Rịa - Vũng Tàu quan tâm và hết sức cần thiết giúp người nuôi cá trên sông Chà Và theo dõi chất lượng nguồn nước bè nuôi 24/24 giờ thông qua điện thoại thông minh, thiết bị sẽ gửi tin nhắn cảnh báo đến số điện thoại của chủ bè khi các thông số nguồn nước ao nuôi ngoài ngưỡng cho phép, báo động hoặc khởi động các thiết bị cung cấp oxy kịp thời để giúp người nuôi có giải pháp kịp thời khắc phục tình trạng cá chết, giúp các nhà quản lý NTTS 
nắm bắt tình trạng kịp thời để quản lý và có giải pháp kịp thời thông báo đến bà con nuôi cá góp phần khắc phục tình trạng cá chết như những năm vừa qua, góp phần ổn định tình hình kinh tế và xã hội tại địa phương.

\section{PHÂN TÍCH VÀ THIẾT KẾ HỆ THỐNG ĐO CHÂT LƯợNG NƯớC NUÔI CÁ LỒNG BÈ TRÊN SÔNG CHÀ VÀ}

\subsection{Phân tích thông số nước nuôi cá lồng và thiết kế hệ thống giám sát chất lượng nước}

Làng bè Chà Và xã Long Sơn được chia làm 8 phân khu và có khoảng 195 hộ nuôi trồng trên diện tích gần 200 mặt nước với tổng số gần 5.600 lồng, chủ yếu là các loại cá bớp, chim trẳng vây vàng, chẽm, mú lai và tôm hùm. Vài ba năm trở về trước, cái tên làng bè Chà Và xã Long Sơn xuất hiện khá nhiều trên các trang mạng cũng như các mặt báo, sự nổi tiếng đó đến từ những vụ xả thải, từ những đợt thiên tai mưa bão khiến thủy sản nuôi lồng chết hàng loạt, đẩy ngư dân vào tình cảnh nợ nần điêu đứng.

Theo đánh giá của Sở NN-PTNT, ngoài nguyên nhân xả thải từ các nhà máy chế biến hải sản, mật độ nuôi dày đặc thì rác thải sinh hoạt hàng ngày phát sinh trên các lồng bè cũng chính là nguyên nhân khiến cho môi trường nước ngày càng ô nhiễm. Vì vậy, những năm gần đây tỷ lệ NTTS trên sông Chà Và thành công giảm $60 \%$ so với 3-4 năm trước.

Theo kết quả quan trắc và phân tích môi trường nước mới nhất tại khu vực nuôi cá biển bằng lồng bè tại cửa sông Chà Và (của Trung tâm Quan trắc Môi trường biển - Viện nghiên cứu hải sản Việt Nam hồi tháng 8-2017) cho thấy, nguồn nước ở khu vực này đã bị suy giảm và ô nhiễm thể hiện qua nồng độ oxy hòa tan trong nước thấp hơn giới hạn cho phép ( $>5 \mathrm{mg} / \mathrm{l})$; nồng độ các thông số N-NO-2, N-NO-3, P-PO43- trong nước cao vượt giới hạn cho phép áp dụng cho nước phục vụ cho mục đích bảo tồn thủy sinh và NTTS. Thêm một nguyên nhân nữa gây cá chết hàng loạt là thời tiết thay đổi đột ngột dẫn đến độ mặn giảm và nhất là việc NTTS với mật độ dày đặc đã gây nên tình trạng thiếu ôxy trong nước. Để nghiên cứu thiết kế hệ thống và tìm hiểu những chỉ tiêu nào quan trọng ảnh hưởng đến sự sống của thủy sản lồng bè chúng tôi đã trao đổi trực tiếp với chủ bè lớn nhất tại xã Long Sơn có kinh nghiệm hơn 10 năm nuôi cá lồng tại sông Chà Và đó là anh Nguyễn Công Biên, anh cho biết 5 thông số quan trọng cần được giám sát là: nhiệt độ, độ $\mathrm{pH}$, độ mặn, oxy hòa tan và nồng độ Clo trong nước. Khi một trong năm thông số trên vượt ngưỡng yêu cầu hệ thống thông báo với chủ bè đồng thời chạy máy sụt khí khẩn cấp thì có thể tránh tình trạng cá chết, do đó chúng tôi xây dựng hệ thống quan trắc chất lượng nước nuôi cá bè có những chức năng sau:

- Đo và giám sát 05 chỉ tiêu chất lượng nước ao nuôi như: nhiệt độ, độ pH, nồng độ muối, oxy hòa tan, nồng độ Chlorine trong nước online 24/24 qua Web-server và GSM/GPRS - Ứng dụng trên điện thoại

- Cảnh báo thông số môi trường nước ao nuôi vượt ngưỡng qua tin nhắn SMS đến chủ ao, đến webserver

- Điều khiển thiết bị sục khí Oxy, máy bơm tự động nếu cần thiết

- Lưu trữ thông số môi trường nước, có thể xem lại trong thời gian 06 tháng đến 01 năm

- Sử dụng cảm biến công nghiệp có độ bền cao

- Hệ thống có thể tự động rữa và bảo quản cảm biến để tăng cường tuổi thọ và kéo dài thời gian hiệu chuẩn.

Sơ đồ thiết kế hệ thống quan trắc chất lượng nước nuôi cá lồng bè được giới thiệu trong hình 3 . Trong hệ thống, bộ điều khiển trung tâm đóng vai trò quan trọng, là thiết bị đầu vào nhận dữ liệu từ các cảm biến và xuất dữ liệu điều khiển, ngoài ra còn là cầu nối liên lạc giữa các thiết bị với nhau, tạo nên một mối liên kết trong hệ thống. Hệ thống đo và giám sát các thông số môi trường được trang bị các bộ cảm biến công nghiệp với độ chính xác cao để thu thập các thông số chỉ tiêu nước cần theo dõi như nhiệt độ, nồng độ $\mathrm{pH}, \mathrm{Oxy}$ hòa tan, nồng độ muối, nồng độ clorine. Các thông số môi trường nước sẽ được cập nhật liên tục và hiển thị trên màn hình giao diện của hệ thống. Hệ thống hoạt động ổn định $24 / 24$ giám sát liên tục các chỉ tiêu môi trường nước, đảm bảo các chỉ tiêu nằm trong giới hạn tốt nhất cho tôm cá phát triển $(5 / 8$ chỉ tiêu môi trường được thiết lập theo bảng chỉ tiêu QCVN 02-19:2014 BNNPTNT do Bộ Nông nghiệp và Phát triển Nông thôn ban hành). Giảm thiểu tối đa cũng như hạn chế tới mức thấp nhất các nguy cơ các thông số môi trường thay đổi đột ngột gây ảnh hưởng xấu đến vật nuôi. Trong trường hợp các thông số môi trường vượt 
ngưỡng cho phép, hệ thống tự động gửi tin nhắn đến chủ bè nuôi để có những biện pháp ứng phó xử lý kịp thời hoặc tự động khởi động máy sục khí oxy và các thiết bị khác nhằm tránh tình trạng cá chết. Ngoài ra hệ thống có thể tự động rửa cảm biến, ngâm cảm biến trong nước ngọt giúp bảo vệ và tăng tuổi thọ cảm biến và giảm thời gian hiệu chuẩn. Toàn bộ hệ thống sử dụng nguồn năng lượng mặt trời nên tiết kiệm điện và có thể lắp đặt ở giữa sông nơi không có nguồn điện lưới.

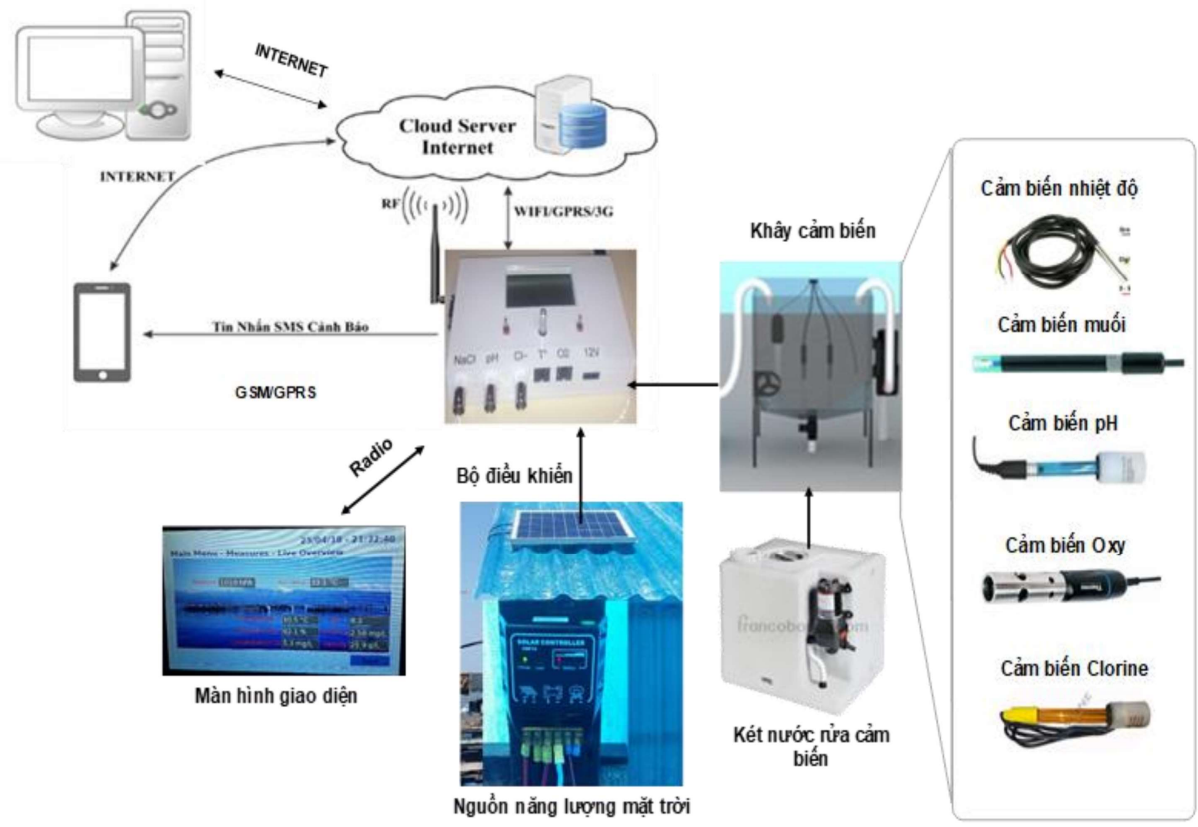

Hình 3: Sơ đồ tổng thể hệ thống quan trắc chất lượng nước tự động nuôi cá lồng bè

\subsection{Phân tích và thiết kế hệ thống cảm biến đo chất lượng nước}

a. Thiết kế mạch cảm biến đo nhiệt độ

Nhiệt độ ảnh hưởng đến tốc độ tăng trưởng và tỉ lệ sống của cá, nhiệt độ tốt nhất cho nuôi tôm cá là 26$32^{\circ} \mathrm{C}$, cần cảnh báo khi nhiệt độ tăng trên $32^{\circ} \mathrm{C}$. Ở nhiệt độ $35^{\circ} \mathrm{C} 100 \%$ tôm cá dưới một tháng tuổi sẽ chết. Trên $40^{\circ} \mathrm{C}$ thì toàn bộ tôm cá sẽ chết. Nhiệt độ thấp thì tôm cá sẽ chậm lớn. Nhiệt độ càng cao thì nước càng ít oxy, trong khi chuyển hóa chất trong cơ thể tôm cá và sự phân hủy các chất bẩn trong nước xảy ra càng nhanh, nghĩa là cần nhiều oxy hơn. Do vậy nhiệt độ cao rất nguy hiểm và có thể dẫn đến thiếu hụt oxy. Hiện tượng thiếu oxy do nóng được gọi là ô nhiễm nhiệt.

Do đó, cần phải giám sát nhiệt độ thường xuyên và khi nhiệt độ vượt $35^{\circ} \mathrm{C}$ cần khởi động hệ thống quạt khoáy đảo nước.

Cảm biến nhiệt độ sử dụng là cảm biến số DS18B20, truyền thông với vi điều khiển qua một dây tín hiệu. Sơ đồ dây kết nối với mạch cảm biến nhiệt độ được giới thiệu trong hình 4.

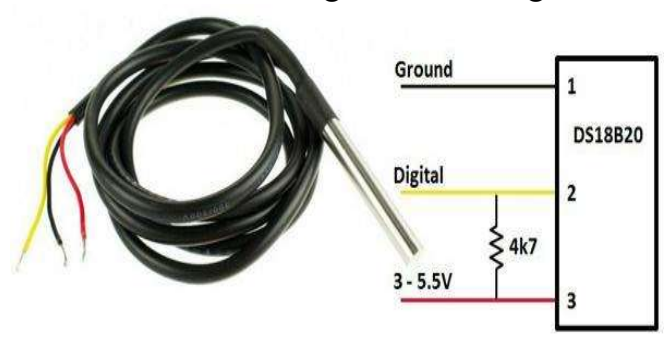

Hình 4: Mạch kết nối với cảm biến nhiệt độ

b. Thiết kế mạch cảm biến đo nồng độ $\mathrm{PH}$ trong nước 
Độ pH thích hợp cho đa số động vật thủy sinh là 6.5-9.0. pH tối đa cho tôm cá là 7.5-8.5. Ngoài ra pH không được dao động quá 0.5 đơn vị trong ngày để tránh sốc cho cá. Thông số $\mathrm{pH}$ dao động do nhiều yếu tố thời tiết, thổ nhưỡng, tảo và sinh vật lạ. Ban ngày tảo hấp thu $\mathrm{CO}_{2}$ để quang hợp nên $\mathrm{pH}$ tăng, ngược lại

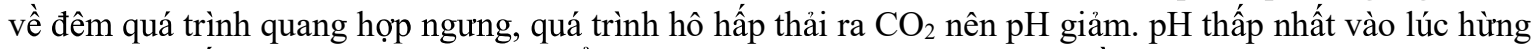
đông, cao nhất vào lúc mặt trời lặn. Để giới hạn ảnh hưởng này thì độ kiềm phải đảm bảo không dưới $100 \mathrm{mg} / 1$.

Cảm biến pH là cảm biến thụ động, có nghĩa là không cần điện áp hoặc nguồn dòng điện. Cảm biến được phân loại là cảm biến lưỡng cực bởi vì đầu ra của điện cực có thể xoay trên và dưới điểm tham chiếu [5].

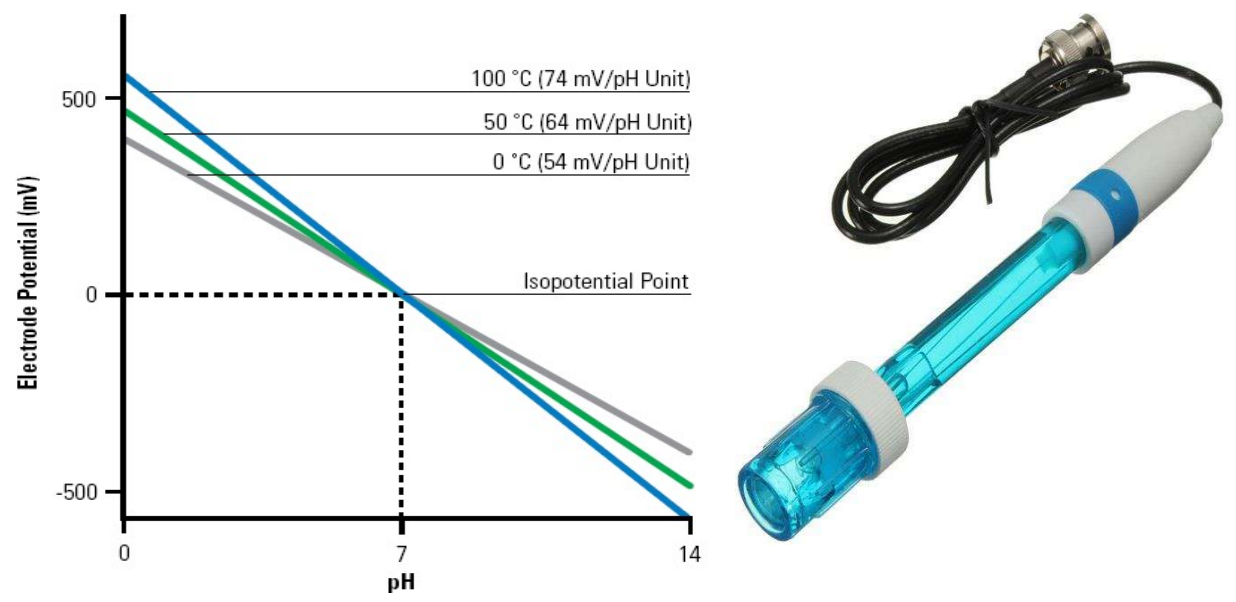

Hình 5: Đặc tính đo của cảm biến đo pH

Cảm biến tạo ra một đầu ra điện áp phụ thuộc tuyến tính vào độ $\mathrm{pH}$ của dung dịch mà nó được đặt vào. Thiết kế một mạch điện để đảm bảo điều kiện tín hiệu cảm biến có thể đọc vào vi điều khiển là rất khó khăn. Có một vài bước cần thực hiện trước khi gửi tín hiệu vào bộ chuyển đổi $\mathrm{A} / \mathrm{D}$ để cung cấp cho bộ vi điều khiển. Đầu tiên, tín hiệu phải được dịch chuyển bởi vì cảm biến $\mathrm{pH}$ tạo ra tín hiệu lưỡng cực. Hầu hết các ứng dụng như PIC hoạt động trên một nguồn cung cấp duy nhất. Bước thứ hai là do trở kháng cao của điện cực đo. Do đó tín hiệu từ cảm biến sẽ được khuếch đại trở kháng đầu vào cao sử dụng IC MCP6N11 (hình 6). Bộ chuyển đổi $\mathrm{ADC}$ (Analog Digital Converter) bên trong vi điều khiển được sử dụng. Điện áp tham chiếu trong giao thức truyền theo chuẩn CAN (Controller Area Network) là $+3.3 \mathrm{~V}$ (AVDD) và $0 \mathrm{~V}$ (AVSS). Do sự chênh điện thế giữa 2 cực cảm biến $\mathrm{pH}$ nên lần đầu tiên sử dụng phải thêm vào một điện áp bù chênh áp giữa cực âm và cực dương, sau đó khuếch đại và cuối cùng được chuyển đổi thành số 10 bit. Điện áp bù thêm vào là $\mathrm{AVDD} / 2$ là $1.65 \mathrm{~V}$.

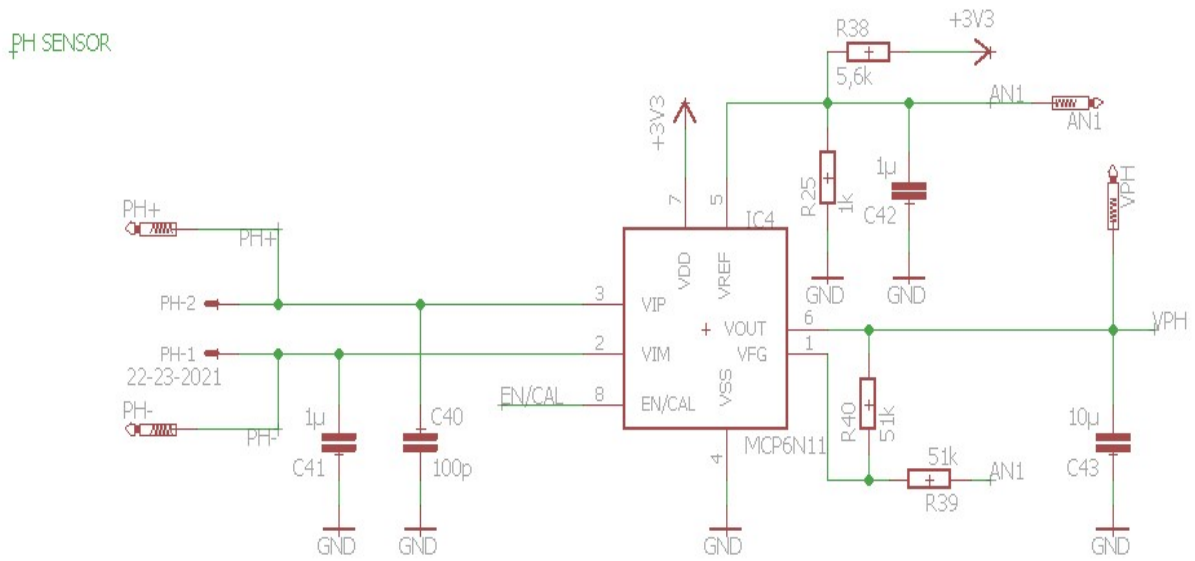

Hình 6: Sơ đồ mạch đo độ $\mathrm{pH}$ trong nước 
c. Thiết kế mạch cảm biến đo độ mặn trong nước

Độ mặn thích hợp cho cá tôm từ 20 - 40 (\%), độ muối thích hợp cho tôm sú và tôm thẻ chân trắng là 5-35 (\%o phần ngàn). Nước ngọt có độ mặn rất thấp, tùy theo vùng mà độ mặn có thể dao động trong khoảng 20$350 \mathrm{mg} / 1(0,02-0,25 \%)$. Ta cảm thấy vị mặn khi độ muối khoảng $1 \%$. Phần lớn các loại tôm cá nước ngọt chịu được độ mặn lên đến $2 \%$. Theo tiêu chuẩn nuôi tôm cá nước lợ lồng bè độ mặn phải đạt $>20 \%$.

Sự thay đổi độ mặn đột ngột sẽ làm cho tôm cá mệt mỏi và có thể chết do đó cần có biện pháp xử lý khi nước mưa tràn vào bè làm giảm độ mặn đột ngột, cũng như bổ sung nước ngọt nếu nước bay hơi làm độ muối tăng quá cao.

Cảm biến muối xác định độ mặn trong dung dịch dựa trên độ dẫn điện. Đầu dò độ mặn đo cường độ dòng điện chạy qua nước là bao nhiêu. Nước có muối hòa tan trong nó sẽ dẫn điện tốt hơn so với nước không có muối hòa tan. Càng nhiều muối hòa tan trong nước thì nước sẽ dẫn điện tốt hơn. Độ mặn sau đó được tính toán từ giá trị độ dẫn điện đo được. Cảm biến này được tích hợp bù cho sự thay đổi độ dẫn điện do nhiệt độ. Cảm biến đo độ mặn trong dự án sử dụng điện cực Platinum (Hình 7). Để tránh hiện tượng điện phân giữa nước biển và dây dẫn cần thiết kế bù nhiễu sử dụng mạch cầu WIEN.

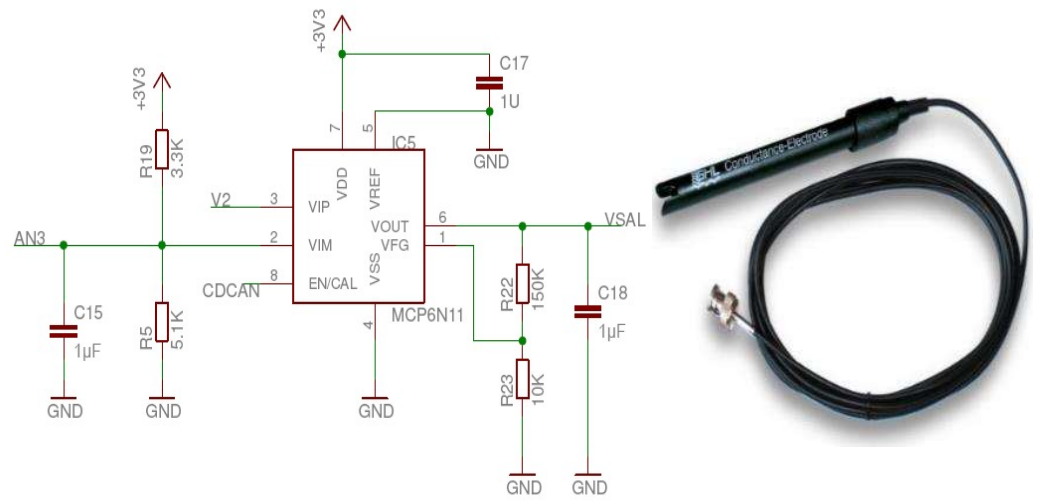

Hình 7: Mạch cảm biến đo độ mặn

d. Thiết kế mạch cảm biến đo oxy hòa tan (DO) trong nước

Ôxy là chất khí cần thiết để sinh vật duy trì sự sống. Thành phần của không khí bao gồm $78 \%$ là nitơ, $21 \%$ ôxy và $1 \%$ các chất khí khác, nghĩa là trong 5 lít không khí có khoảng 1,5 gam ôxy. Không khí đáp ứng đầy đủ nhu cầu ôxy cho các loài sống trên cạn và có thể dễ dàng xáo trộn, luân chuyển. Tuy nhiên, trong môi trường thủy sinh, chỉ có khoảng 1 gam ôxy trong 100 lít nước lạnh, thậm chí nồng độ ôxy bão hòa còn thấp hơn khi nước nóng lên.

Oxy hoàn tan (DO: Dessolved Oxygen) là lượng oxy hòa tan trong nước cần thiết cho sự hô hấp của các sinh vật thủy sinh. Nước nuôi tôm cá đảm bảo cho oxy hòa $\tan (\mathrm{DO})=3,5 \mathrm{mg} / \mathrm{l}$, nhưng tối ưu nhất là $>$ $5 \mathrm{mg} / \mathrm{l}$. Oxy hòa tan vừa là dưỡng khí cho tôm cá, vừa là chất tham gia vào quá trình hủy thức ăn thừa và chất thải. Nếu thiếu oxy tôm cá sẽ bị ngạt và trong nước sinh ra các chất độc như amoniac, suynphua hydro và nitric rất hại cho con nuôi.

Mặc dù oxy hoà tan (DO) thường được hiển thị dưới dạng mg/L hoặc ppm, các cảm biến DO không đo lượng oxy thực tế trong nước, thay vào đó nó đo áp suất riêng của oxy trong nước. Áp suất khí oxy phụ thuộc vào độ mặn và nhiệt độ.

Các cảm biến Galvanic DO bao gồm hai điện cực: một cực dương và cực âm, đều được nhúng trong chất điện phân (bên trong lõi cảm biến). Một màng thẩm thấu oxy tách anode và cathode ra khỏi nước đang được đo. Ôxy khuếch tán qua màng. Áp suất cao hơn cho phép nhiều oxy khuếch tán qua màng và dòng điện sẽ được tạo ra nhiều hơn. Điện áp thực tế từ cảm biến là milivolts. Điều này đạt được bằng cách truyền dòng điện qua một thermistor (điện trở thay đổi nhiệt độ đầu ra). Hạn chế của cảm biến đo oxy bằng điện cực các màng mau hỏng do cặn bám vào, độ chính xác không cao và thời thời gian đáp ứng chậm. Để khắc phục nhược điểm trên trong nghiên cứu này chúng tôi sử dụng cảm biến đo oxy hòa tan quang điện.

Nguyên lý phương pháp đo oxy hòa tan bằng nguyên lý quang LDO (Luminescent Dissolved Oxygen) nhằm để xác định oxy hòa tan trong nước. Công nghệ LDO dựa trên ánh sáng màu xanh dương, mang lại 
lợi ích như độ chính xác cao, tuổi thọ lâu dài và giảm chi phí bảo trì, ưu điểm của phương pháp này thích hợp để thay thế các phương pháp điện hóa thông thường.

Nguyên tắc LDO là dựa trên hiện tượng vật lý của sự phát quang. Một số vật liệu phát ra ánh sáng khi bị kích thích bởi một nguồn kích thích khác không phải do nhiệt. Trong trường hợp của nguyên lý LDO, nguồn kích thích là ánh sáng. Nếu kết hợp giữa ánh sáng kích thích và chiều dài sóng của ánh sáng kích thích phù hợp, cường độ phát quang và thời gian cần để ánh sáng tan biến là phụ thuộc vào nồng độ oxy xung quanh vật liệu.

Nguyên lý đo oxy hòa tan bằng quang được mô tả trên hình 8 . Khi đèn LED xanh phát ra ánh sáng nó gây cho phần tử phát quang nhúng trong lá cảm biến khí phát ra các photon đỏ, cảm biến RDO sẽ đo "phase" của tín hiệu trả về so sánh với tín hiệu kích thích dựa trên "thời gian sống" hay "cường độ" phát quang. Sự hiện diện oxy trong lá làm nguội đi sự phát quang và gây ra một phase bị thay đổi tín hiệu trả về được thu được photodiode. Chênh lệch phase giữa ánh sáng kích thích màu xanh và ánh sáng đỏ trả lại được đo, kết quả định lượng được nồng độ oxy hòa tan.

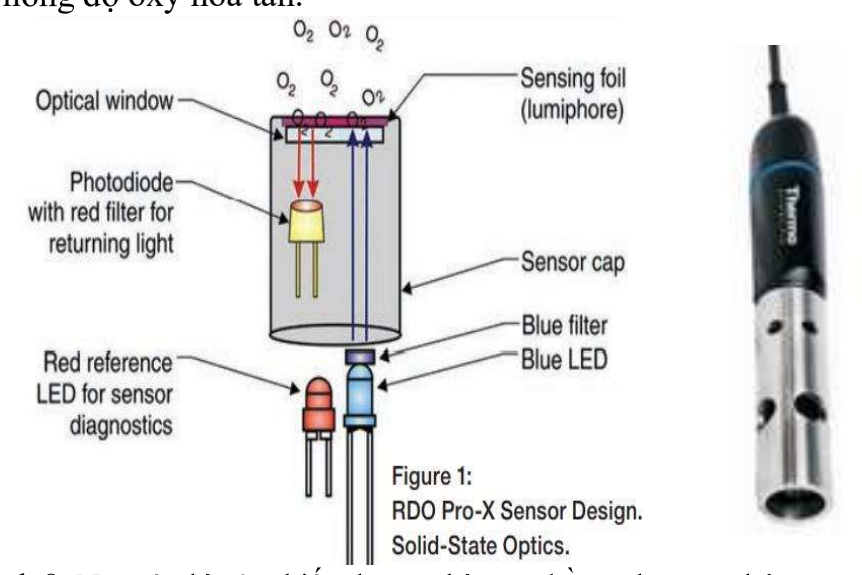

Hình 8: Nguyên lý cảm biến đo oxy hòa tan bằng phương pháp quang điện

Cảm biến đo nồng độ oxy trong dự án là Thermo scientific 0877010 MD. Đây là loại cảm biến sử dụng kỹ thuật công nghệ quang, truyền thông với vi điều khiển sử dụng giao thức chuẩn công nghiệp MODBUS. Khi đo thành phần oxy trong nước phụ thuộc vào áp suất khí quyển. Do đó trong mạch thêm vào một $\mathrm{IC}$ đo áp suất khí quyển BPM180 truyền thông với vi điều khiển thông qua chuẩn I2C.

e. Thiết kế mạch cảm biến đo Clorine trong nước

Dọc sông Chà Và các nhà máy công nghiệp thường dùng Chlorine để vệ sinh và xả xuống nước, dư lượng của khí Clo có thể gây độc cho vật nuôi, đặc biệt là ấu trùng tôm. Khi lượng Chlorine xử lý trong nước dư, chúng sẽ tác dụng lên cá như oxy hóa tế bào mang của cá. Quá trình oxy hóa gây ta kích thích, phá hủy và tổn thương tế bào mang cá, cá tăng quá trình tiết dịch nhầy, viêm màng gây phòng mang cá. Sự thay đổi cấu trúc mang cá sẽ làm giảm khả năng hô hấp và hiệu quả điều chỉnh áp suất thẩm thấu. Khi nồng độ Clo trong nước cao $(>4 \mathrm{mg} / \mathrm{l})$ cá sẽ bị ngộ độc Clo, khi bị ngộ độc Clo nhịp hô hấp của cá tăng mạnh, cá có thể chết do giảm oxy trong máu. Nên chạy sục khí, máy quạt nước để loại bỏ tồn dư của Chlorine trong ao nuôi.

Clo tự do trong nước bao gồm hai hóa chất: axit hypochlorous $(\mathrm{HOCl})$ và ion hypochlorite $(\mathrm{OCl})$ khi Clorine được đưa vào nước để khử trùng.

Cảm biến đo Clorine dư sử dụng phương pháp dòng không đổi là kỹ thuật điện hóa đo sự thay đổi của dòng sinh ra từ phản ứng hóa học xảy ra tại các điện cực. Dòng điện được sinh ra tỷ lệ với nồng độ chất phân tích. Một sensor điện hóa thông thường gồm hai điện cực riêng biệt - điện cực âm anốt và điện cực dương catốt (ví dụ cặp điện cực $\mathrm{Ag} / \mathrm{Pt}$ hay $\mathrm{Cu} / \mathrm{Au}$ ). Thông thường, các điện cực được bao bọc bởi 1 màng có chứa chất điện ly để giúp chọn lọc chất phân tích tốt hơn. Ngoài ra còn có một điện thế không đổi được áp vào giữa các điện cực. 


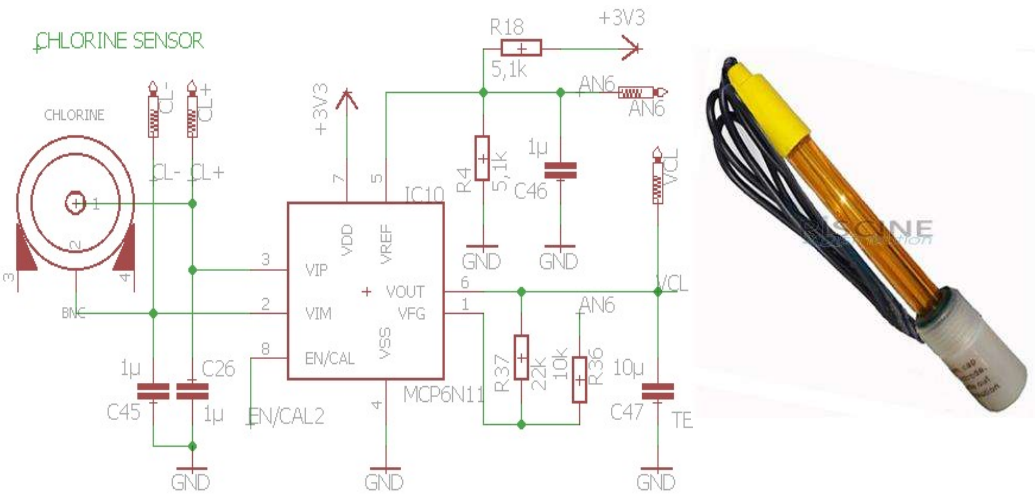

Hình 9: Nguyên lý và cảm biến đo Clorine dư trong nước

\subsection{Phân tích và thiết kế mạch điều khiển}

Mạch điều khiển hệ thống được chế tạo trình bày trên hình 10 bao gồm các khối chức năng như: khối nguồn, khối điều khiển, khối cảm biến, khối hiển thị LCD, khối công suất, khối truyền thông Radio, khối truyền thông GSM/GPRS (Modun SIM800L), khối Ethernet.

Bộ điều khiển hệ thống sử dụng sản phẩm của hãng Microchip đó là vi điều khiển 8 bit PIC18F67J11, bộ vi điều khiển này có 128 byte FLASH và 128 Kbytes RAM. Tín hiệu đồng hồ được tạo thành bởi một tinh thể thạch anh $20 \mathrm{MHz}$. Vi điều khiển này lý tưởng cho các ứng dụng $3 \mathrm{~V}$ có giá thành cao, đòi hỏi giao tiếp nối tiếp linh hoạt với bốn cổng nối tiếp: các cổng nối tiếp đồng bộ kép $\left(\mathrm{I}^{2} \mathrm{C}^{\mathrm{TM}}\right.$ và $\left.\mathrm{SPI} \mathrm{TM}^{\mathrm{T}}\right)$ và các cổng nối tiếp không đồng bộ kép. Một lượng lớn bộ nhớ chương trình Flash làm cho nó lý tưởng cho các bảng thiết bị đo đạc, TCP / IP cho phép các ứng dụng nhúng cũng như các ứng dụng giám sát và kiểm soát công nghiệp. PIC18F67J11 là một cải tiến của họ PIC18F67J10, bao gồm bộ dao động nội bộ 8MHz, tiêu thụ công suất thấp hơn và khả năng mô phỏng EEPROM cải tiến thông qua khả năng ghi từ Flash.

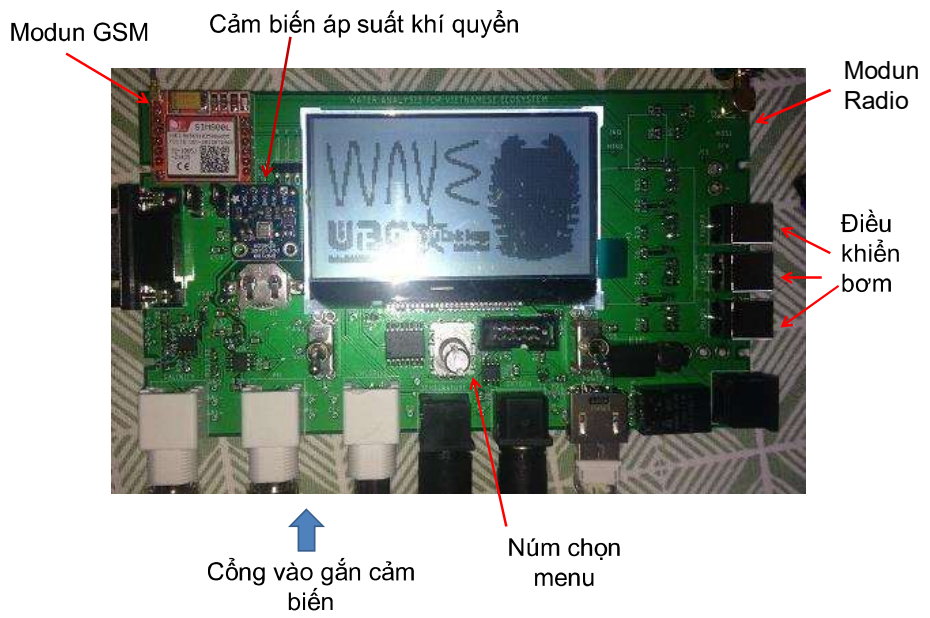

Hình 10: Thi công mạch điều khiển hệ thống với PIC18F67J11

\subsection{Tính chọn nguồn pin mặt trời cho hệ thống}

Tính chọn công suất pin mặt trời cho hệ thống dựa vào tổng công suất tiêu thụ của các thiết bị trong hệ thống, giả sử hệ thống thiết kế lấy mẫu và đo tự động 01 giờ $/ 1$ lần, tổng thời gian một chu kỳ đo mất 5 phút. Sơ đồ kết nối và công suất tiêu thụ được tính như hình 11.

- Tính số watt-hour của tấm pin mặt trời cung cấp (PV module): $\mathrm{PVM}=1.3 \times 182.4 \mathrm{wh}=237.12$ wh

- Tính watt-peak của pin mặt trời: $\mathrm{Wp}=237.12 \mathrm{wh} / 5=47.424 \mathrm{wp}$ (Mức hấp thu năng lượng mặt trời tại một địa điểm của nước Việt $\mathrm{Nam}$ là $5 \mathrm{kWh} / \mathrm{m} 2 /$ ngày). Chọn tấm pin $60 \mathrm{Wp}$. 
- Dung lượng Ác quy (Ah): $A h=\frac{182.4}{0.85 \times 0.6 \times 12}=29.8 \mathrm{Ah}$

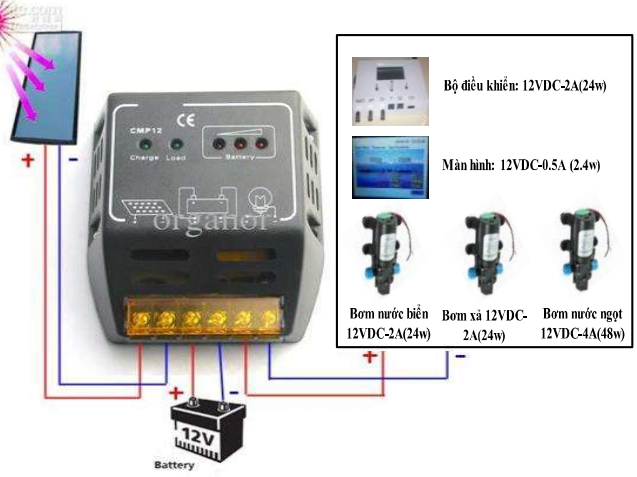

\begin{tabular}{|l|l|l|l|}
\hline TT & \multicolumn{1}{|c|}{ Tên thiết bị } & \multicolumn{1}{|c|}{$\begin{array}{c}\text { TG hoạt động/1 } \\
\text { ngày }\end{array}$} & $\begin{array}{c}\text { Công suất tiêu thụ / } \\
\text { ngày }\end{array}$ \\
\hline 1 & Bộ điều khiển & $5 \mathrm{p} \times 24=2 \mathrm{~h}$ & $24 \mathrm{w} \times 2 \mathrm{~h}=48 \mathrm{wh}$ \\
\hline 2 & Màn hình & $60 \mathrm{p} \times 24=24 \mathrm{~h}$ & $2.4 \mathrm{w} \times 24 \mathrm{~h}=57.6 \mathrm{wh}$ \\
\hline 3 & Bơm nước biển & $2 \mathrm{p} \times 24 \mathrm{~h}=0.8 \mathrm{~h}$ & $24 \mathrm{w} \times 0.8 \mathrm{~h}=19.2 \mathrm{wh}$ \\
\hline 4 & Bơm xả & $2 \mathrm{p} \times 24 \mathrm{~h}=0.8 \mathrm{~h}$ & $24 \mathrm{w} \times 0.8 \mathrm{~h}=19.2 \mathrm{wh}$ \\
\hline 5 & Bơm nước ngọt & $2 \mathrm{p} \times 24 \mathrm{~h}=0.8 \mathrm{~h}$ & $48 \mathrm{w} \times 0.8 \mathrm{~h}=38.4 \mathrm{wh}$ \\
\hline \multicolumn{3}{|c|}{ Tổng công suất tiêu thụ $(\mathrm{Wh}):$} & $\mathbf{1 8 2 . 4}$ wh \\
\hline
\end{tabular}

Hình 11: Sơ đồ kết nối và công suất tiêu thụ các thiết bị

\subsection{Truyền dữ liệu lên webserver}

Dữ liệu sau khi đo sẽ được truyền lên database của web-server thông qua giao thức truyền GPRS/GSM sử dụng mô đun SIM800L. Nếu có thông số vượt ngưỡng, hệ thống sẽ gửi dữ liệu qua tin nhắn SMS đến điện thoại của chủ bè. Sơ đồ kết nối giữa vi điều khiển PIC18F67J11 và mô đun SIM800L được thể hiện trên hình 12 .

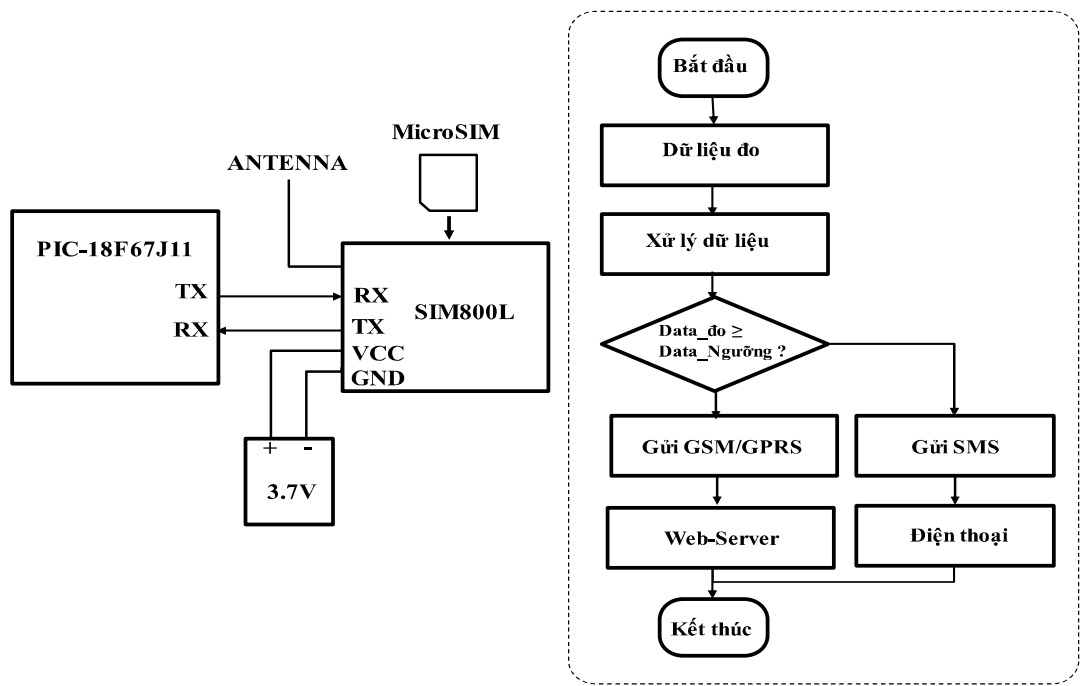

Hình 12: Gừi dữ liệu đo lên Web-Server và Điện thoại

\section{THỰC NGHIỆM VÀ KẾT QUẢ ĐẠT ĐƯợC}

\subsection{Cài đặt và vận hành hệ thống}

Mô hình hệ thống đo và giám sát chất lượng nước thời gian thực được lắp đặt thử nghiệm tại bè nuôi của anh Nguyễn Công Biên có diện tích khoảng $500 \mathrm{~m}^{2}$ với gần 100 lồng bè, bè nuôi chủ đạo các loại thủy sản như: cá bớp, cá chim, cá cam, cá hồng mỹ, tôm xanh, tôm hùm, hào... 


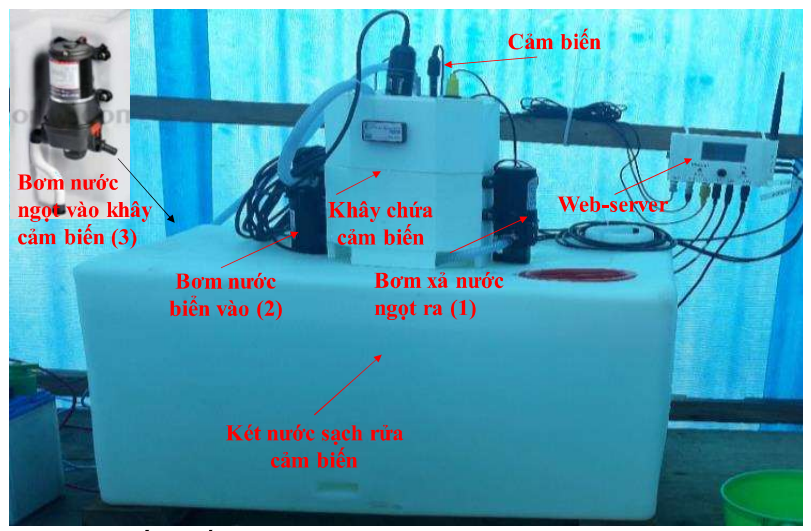

Hình 13: Hệ thống lắp đặt tại bè nuôi của anh Nguyễn Công Biên

Trình tự hoạt động của hệ thống được mô tả theo các bước sau: Bước 1: Hiệu chuẩn cảm biến; Bước 2: Cài đặt thông số hệ thống; Bước 3: Hoạt động hệ thống.

\section{Bước 1: Hiệu chuẩn cảm biến}

Tất cả các cảm biến điện hóa lần đầu tiên trước khi hoạt động phải được hiệu chuẩn (trừ cảm biến oxy: cảm biến công nghệ quang). Trình tự quá trình hiệu chuẩn cảm biến được thực hiện như trên sơ đồ hình 14.

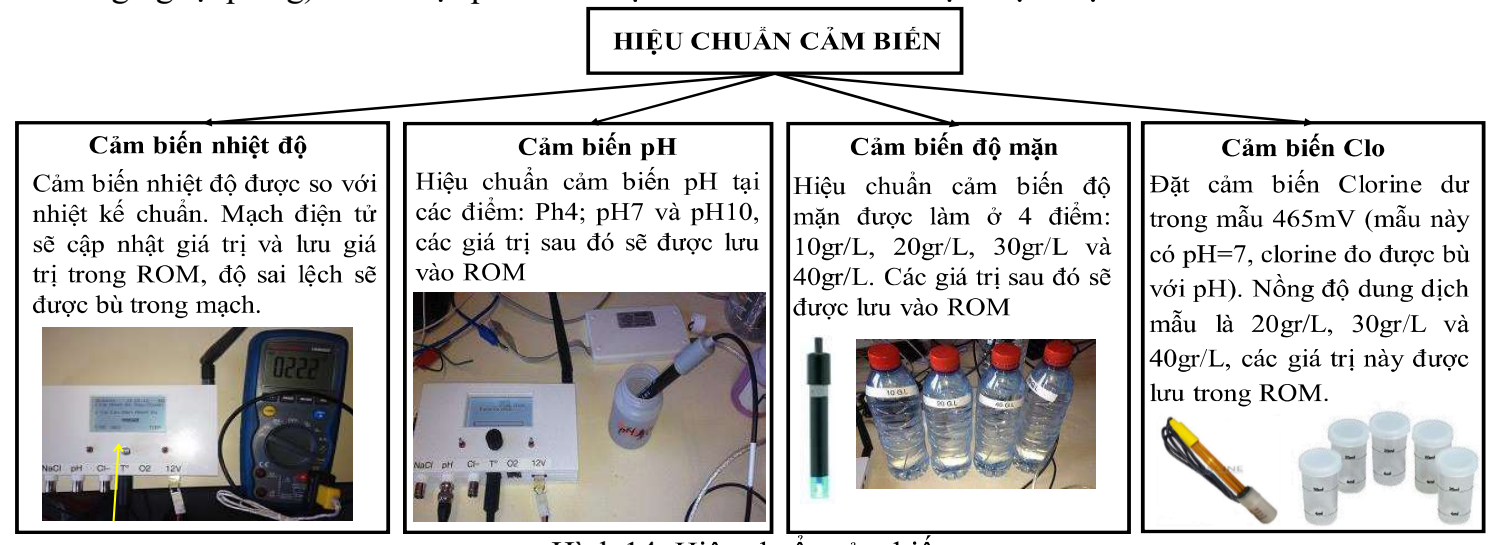

Hình 14: Hiệu chuẩn cảm biến

\section{Bước 2: Cài đặt thông số hệ thống}

Trước khi hệ thống làm việc cần cài đặt thông số cho hệ thống, tùy trường hợp cụ thể mà chế độ cài đặt khác nhau.

- Cài đặt truyền thông: Gắn SIM điện thoại vào hệ thống và cài đặt số điện thoại muốn gửi tin nhắn cảnh báo khi một trong số đo vượt ngưỡng cài đặt thấp hoặc cao.

- Cài đặt báo động: Để cảnh báo và gửi tin nhắn đến điện thoại của chủ bè nuôi khi một thông số vượt ngưỡng chúng ta phải cài đặt ngưỡng giới hạn trên và dưới cho các thông số nước (nhiệt độ, pH, độ mặn, Chlorine, oxy).

- Cài đặt thông số cho bơm và thời gian rửa cảm biến: Tùy theo từng trường hợp có thể cài đặt tốc độ bơm và thời gian rửa cảm biến.

\section{Bước 3: Hoạt động hệ thống}

Hệ thống có 02 chế độ hoạt động: chế độ hoạt động bằng tay (Manual mode) và chế độ làm việc tự động (Auto mode). Trình tự hoạt động của hệ thống được trình bày trên lưu đồ hình 16.

- Chế độ hoạt động bằng tay: Bật công tắc nguồn (1) và chuyển công tắc (2) sang chế độ chạy bằng tay. Trong menu chính chỉnh nút xoay và nhấn xác nhận (3) ở mục "ĐO”, bơm 2 bắt đầu chạy và bơm nước ra khỏi bồn chứa cảm biến. Quá trình này có thể dừng lại nếu nhấn nút (3). Điều chỉnh 
nút tới mục bơm 1 và cho bơm 1 chạy để hút nước vào bồn chứa cảm biến. Sau khi bồn đầy nước quá trình đo bắt đầu thực được thực hiện

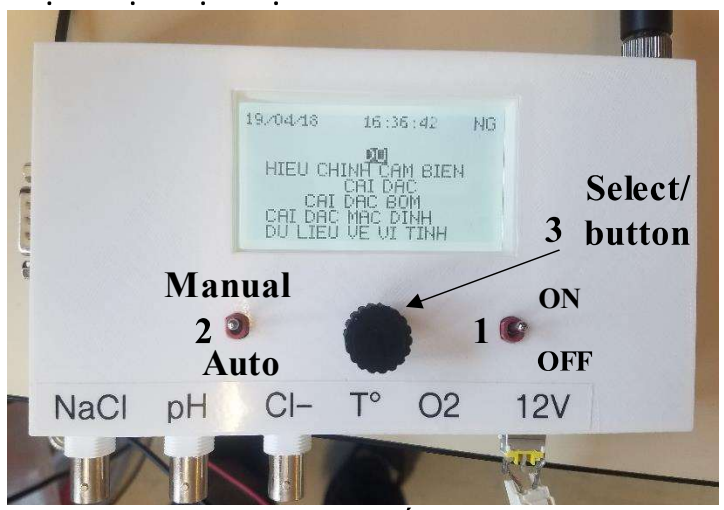

Hình 15: Cài đặt chế độ vận hành

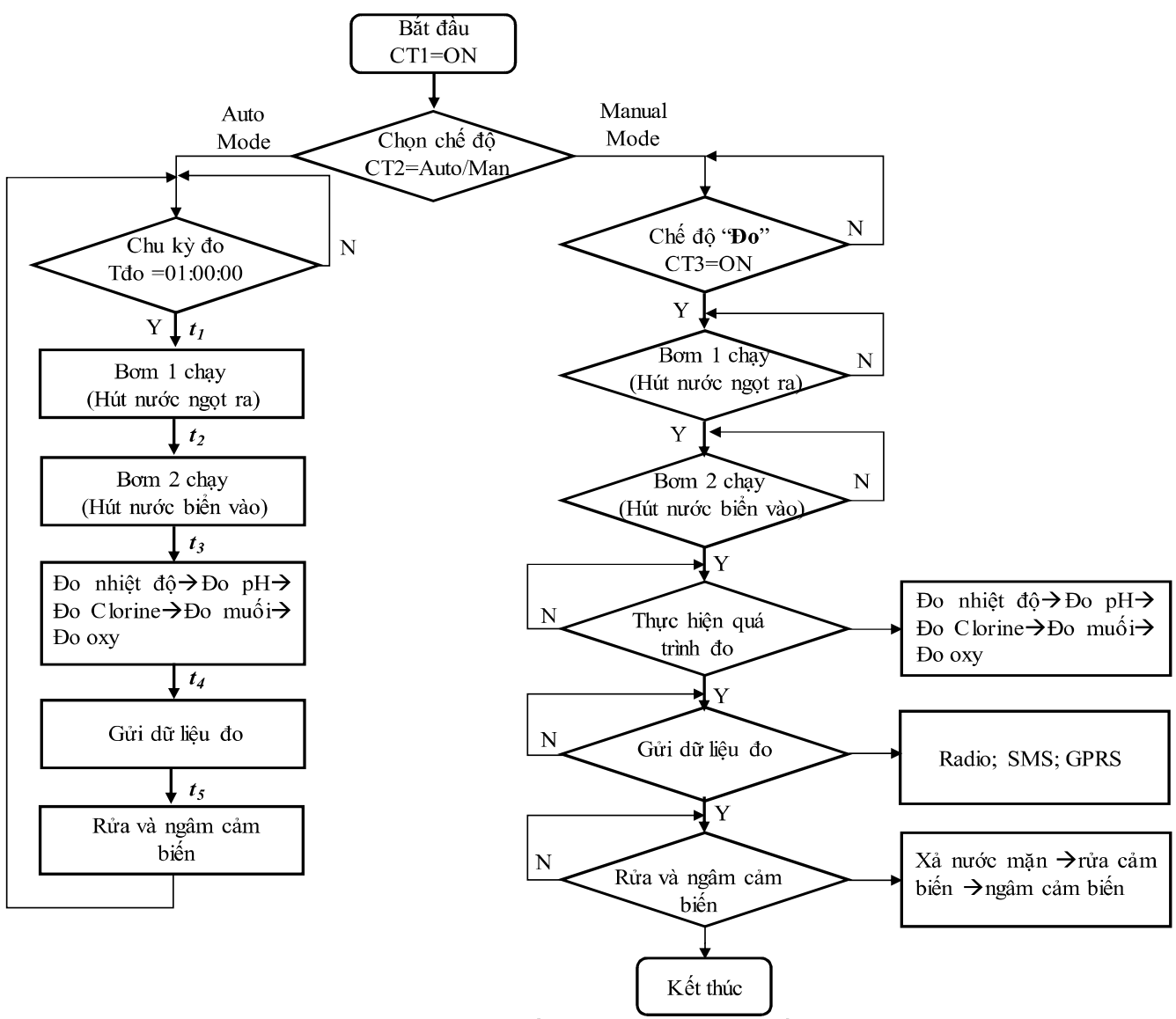

Hình 16: Lưu đồ hoạt động của hệ thống

\subsection{Kết quả đạt được}

- Nguồn cung cấp: Hệ thống làm việc đọc lập và ổn định với nguồn điện pin mặt trời, không cần nguồn lưới.

- Kiểm chứng và đánh giá kết quả đo: 

NUÔI THỦY SẢN NƯỚC LỞ LÔNNG BÈ LE NGOC TRAN

Quá trình thực nghiệm đo và kiểm tra hệ thống nghiên cứu sẽ được đối sánh với các thiết bị đo hiện có trên thị trường. Các dụng cụ đo đối sánh gồm: đo $\mathrm{Ph}$ và nhiệt độ sử dụng máy đo $\mathrm{pH}$ Adwan Instruments $\mathrm{AD} 132$ (Romania), đo độ mặn sử dụng máy đo Hana HI993310 (Emin), đo oxy hòa tan sử dụng máy HD3030 (Singapore) và đo nồng độ Clo dư sử dụng máy đo Hanna HI96701 (Italia). Kết quả đo được thực hiện liên tục trong 4 giờ ngày 07/05/2018 sẽ được hiển thị từ bảng 1 đến bảng 5 .

Bảng 1: Kết quả đo nhiệt độ của 02 dụng cụ

\begin{tabular}{|c|c|c|c|}
\hline $\begin{array}{c}\text { Thời } \\
\text { gian }\end{array}$ & Hệ thống đo & $\begin{array}{c}\text { Thiết bị đo } \\
\mathrm{AD} 132\end{array}$ & Sai lệch \\
\hline $12 \mathrm{~h}$ & $30,1^{\circ} \mathrm{C}$ & $30^{\circ} \mathrm{C}$ & $0,1^{\circ} \mathrm{C}$ \\
\hline $13 \mathrm{~h}$ & $30,3^{\circ} \mathrm{C}$ & $30,5^{\circ} \mathrm{C}$ & $-0,2^{\circ} \mathrm{C}$ \\
\hline $14 \mathrm{~h}$ & $29,9^{\circ} \mathrm{C}$ & $30^{\circ} \mathrm{C}$ & $-0,1^{\circ} \mathrm{C}$ \\
\hline $15 \mathrm{~h}$ & $27,1^{\circ} \mathrm{C}$ & $27^{\circ} \mathrm{C}$ & $0,1^{\circ} \mathrm{C}$ \\
\hline
\end{tabular}

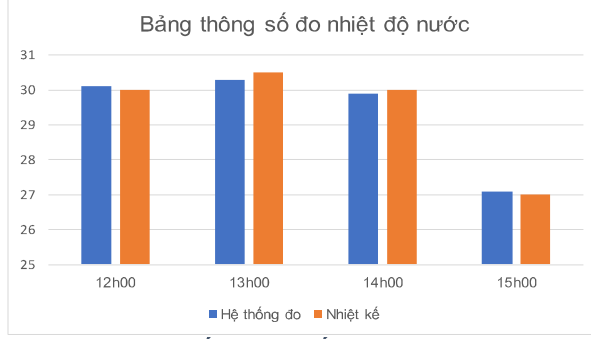

Hình 17: Đối sánh kết quả đo nhiệt độ

Bảng 2: Kết quả đo $\mathrm{pH}$ của 02 dụng cụ

\begin{tabular}{|c|c|c|c|}
\hline $\begin{array}{c}\text { Thời } \\
\text { gian }\end{array}$ & Hệ thống đo & $\begin{array}{c}\text { Thiết bị đo } \\
\text { AD132 }\end{array}$ & $\begin{array}{c}\text { Sai } \\
\text { lệch }\end{array}$ \\
\hline $12 \mathrm{~h}$ & 8,37 & 8,3 & 0,07 \\
\hline $13 \mathrm{~h}$ & 8,8 & 8,7 & 0,1 \\
\hline $14 \mathrm{~h}$ & 8,47 & 8,5 & $-0,03$ \\
\hline $15 \mathrm{~h}$ & 8,15 & 8,2 & $-0,05$ \\
\hline
\end{tabular}

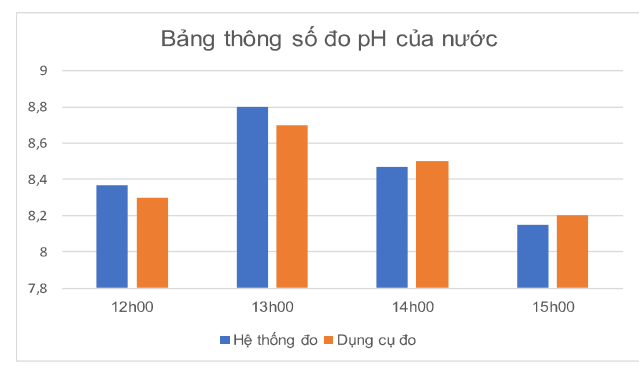

Hình 18: Đối sánh kết quả đo $\mathrm{pH}$

Bảng 2 cho thấy kết quả $\mathrm{pH}$ đo được không sai lệch nhiều. Giá trị $\mathrm{pH}$ đo được ở các vị trí quan trắc dao động trong khoảng từ 8,15 đến 8,8 . Nhìn chung tại tất cả các vị trí quan trắc giá trị pH đều thỏa mãn tiêu chuẩn chất lượng nước nuôi trồng thủy tỉnh BRVT và QCVN 02-19:2014/BNNPTNT.

\begin{tabular}{|c|c|c|c|}
\multicolumn{4}{|c|}{ Bảng 3: Kết quả đo độ mặn của 02 dụng cụ } \\
\hline $\begin{array}{c}\text { Thời } \\
\text { gian }\end{array}$ & $\begin{array}{c}\text { Hệ thống đo } \\
(\% \mathrm{o})\end{array}$ & $\begin{array}{c}\text { Hana } \\
\text { HI993310 } \\
(\% \mathrm{o})\end{array}$ & $\begin{array}{c}\text { Sai lệch } \\
(\% \mathrm{o})\end{array}$ \\
\hline $12 \mathrm{~h}$ & 19,3 & 19,2 & 0,1 \\
\hline $13 \mathrm{~h}$ & 19,7 & 19,7 & 0,0 \\
\hline $14 \mathrm{~h}$ & 18,6 & 18,5 & 0,1 \\
\hline $15 \mathrm{~h}$ & 16,4 & 16,3 & 0,1 \\
\hline
\end{tabular}

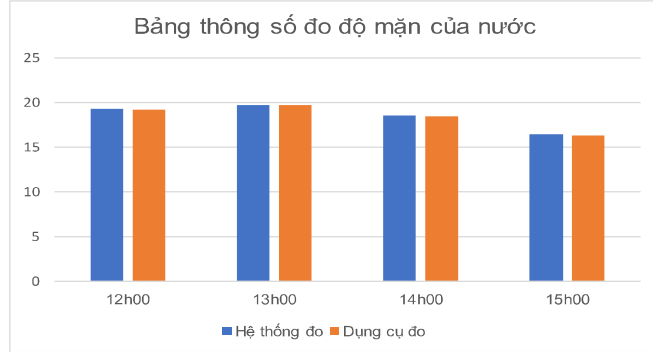

Hình 19: Đối sánh kết quả đo độ mặn

Bảng 3 cho thấy độ mặn giữa 02 dụng cụ đo là tương đối giống nhau, độ mặn cao nhất $19,7 \%$ o, vị trí thấp nhất $16,4 \%$ o sai lệch cao nhất là $0,1 \%$ o. Tại các đợt quan trắc lần 3 và 4 khi thủy triều lên độ mặn sẽ tăng dần, nhưng do ảnh hưởng của mưa nên độ mặn vẫn được cân bằng. 
Bảng 4: Kết quả đo oxy hòa tan của 02 dụng cụ

\begin{tabular}{|c|c|c|c|}
\hline $\begin{array}{c}\text { Thời } \\
\text { gian }\end{array}$ & $\begin{array}{c}\text { Hệ thống đo } \\
(\mathrm{mg} / \mathrm{l})\end{array}$ & $\begin{array}{c}\text { HD3030 } \\
(\mathrm{mg} / \mathrm{l})\end{array}$ & $\begin{array}{c}\text { Sai lệch } \\
(\mathrm{mg} / \mathrm{l})\end{array}$ \\
\hline $12 \mathrm{~h}$ & 6,1 & 5,9 & 0,2 \\
\hline $13 \mathrm{~h}$ & 6,4 & 6,3 & 0,1 \\
\hline $14 \mathrm{~h}$ & 6,8 & 6,6 & 0,2 \\
\hline $15 \mathrm{~h}$ & 8,8 & 8,6 & 0,2 \\
\hline
\end{tabular}

Bảng 4 cho thấy nồng độ oxy hòa tan giữa 02 dụng cụ đo là tương đối giống nhau Nhìn chung giá trị DO tại tất cả các vị trị ở mọi thời điểm đều đạt tiêu chuẩn nước nuôi trồng thủy sản theo tiêu chuẩn chất lượng nước nuôi trồng thủy sản của tỉnh BRVT và QCVN 0219:2014/BNNPTNT. Trong đó cao nhất là $8,8 \mathrm{mg} / 1$ lúc $15 \mathrm{~h}$ do mưa lớn làm cho độ oxy trong nước tăng theo, thấp nhất là $6,1 \mathrm{mg} / 1$ lúc $12 \mathrm{~h}$ nhưng vẫn đạt tiêu chuẩn.

Bảng 5: Bảng kết quả đo chlorine dư

\begin{tabular}{|c|c|c|c|}
\hline $\begin{array}{c}\text { Thời } \\
\text { gian }\end{array}$ & $\begin{array}{c}\text { Hệ thống đo } \\
(\mathrm{mg} / \mathrm{l})\end{array}$ & $\begin{array}{c}\text { Hanna } \\
\text { HI96701 } \\
(\mathrm{mg} / \mathrm{l})\end{array}$ & $\begin{array}{c}\text { Sai lệch } \\
(\mathrm{mg} / \mathrm{l})\end{array}$ \\
\hline $12 \mathrm{~h}$ & 0,5 & 0,5 & 0 \\
\hline $13 \mathrm{~h}$ & 0,55 & 0,5 & 0,05 \\
\hline $14 \mathrm{~h}$ & 0,8 & 0,8 & 0 \\
\hline $15 \mathrm{~h}$ & 1,0 & 1,1 & $-0,1$ \\
\hline
\end{tabular}

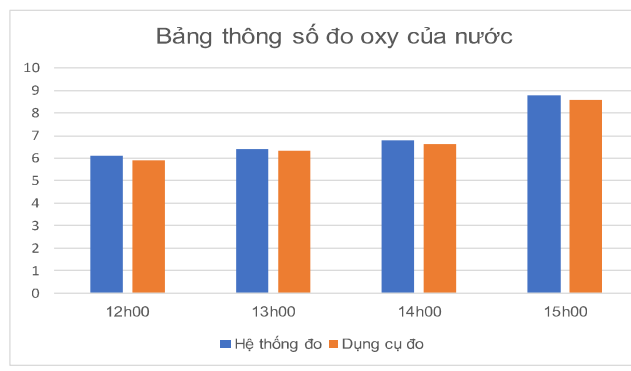

Hình 20: Đối sánh kết quả đo oxy hòa tan

\section{- Kết quả thực nghiệm gửi dữ liệu lên web-serer:}

Dữ liệu sau khi đo sẽ được cập nhật trên web-server, nếu có thông số vượt ngưỡng hệ thống sẽ gửi tin nhắn SMS đến chủ bè. Kết quả thực nghiệm dữ liệu đo cập nhật trên web-server thể hiện trong hình 22.

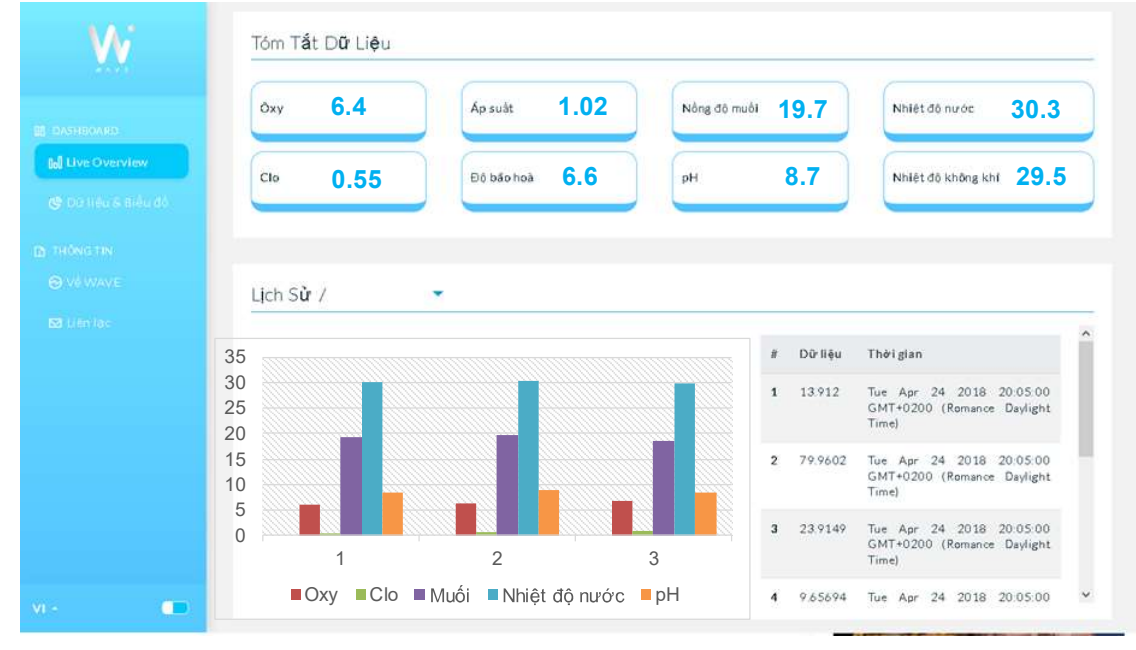

Hình 22: Kết quả dữ liệu đo cập nhật lên Web-Server

Từ kết quả phân tích trên cho thấy nồng độ chlorine giữa 02 dụng cụ đo là tương đối giống nhau, nồng độ chlorine cao nhất $1,0 \mathrm{mg} / \mathrm{l}$ và thấp nhất là $0,5 \mathrm{mg} / 1$ sai lệch cao nhất là $0,1 \mathrm{mg} / 1$. Tại các đợt quan trắc lần 3 và 4 nồng độ chlorine tăng lên do xả thải của nhà máy nhưng nồng độ chlorine vẫn nằm trong ngưỡng an toàn $<4 \mathrm{mg} / \mathrm{l}(\mathrm{QCVN})$. 


\section{KẾT LUẬN}

Dựa trên kết quả chạy thử nghiệm trên khu lồng bè nuôi thủy sản của chủ hộ Nguyễn Công Biên, khi sử dụng hệ thống đo chất lượng nước của dự án, mang lại những ưu điểm như sau:

- Hệ thống chạy ổn định với nguồn điện mặt trời nên tiết kiệm điện và có thể lắp đặt ở những nơi không cần điện lưới.

- Hệ thống tự động lấy mẫu, đo, giám sát 05 chỉ tiêu nước liên tục 24/24 và gửi dữ liệu lên webserver.

- Kết quả đo so sánh với các dụng cụ đo cầm tay (bảng 1-5), cho thấy hệ thống làm việc chính xác và ổn định.

- Thông số đo được hiển thị trên màn hình bằng tiếng Việt rất thuận tiện cho người dùng.

- Sử dụng cảm biến công nghiệp có độ chính xác cao, có hệ thống tự động rửa cảm biến và bảo quản cảm biến trong nước ngọt nên tăng tuổi thọ và duy trì độ chính xác cảm biến, kéo dài thời gian hiệu chuẩn.

- Lưu trữ dữ liệu đo trong thời gian 6 tháng đến 1 năm, vẽ đồ thị và làm báo cáo.

Hiện tại việc nuôi trồng thủy sản tại tỉnh BRVT vẫn còn sử dụng các phương pháp nuôi truyền thống, không kiểm soát được nguồn nước, phó mặt cho thiên nhiên, nên hiệu quả không cao và nhiều rủi ro. Trong vòng 5 năm tới để nâng cao năng suất, chất lượng nuôi và sản phẩm mang tính cạnh tranh cao buộc người nuôi phải áp dụng công nghệ kỹ thuật cao vào nuôi thủy sản. Do đó nhu cầu thị trường về hệ thống đo, giám sát và cảnh báo chất lượng nước tự động phục vụ nuôi thủy sản trong tương lai là rất lớn.

\section{TÀI LIỆU THAM KHẢO}

[1] Cao L, Wang W, Yang Y, Yang C, Yuan Z, Xiong S, Diana J. Environmental impact of aquaculture and countermeasures to Aquaculture Pollution in China. Env. Sci. Pollut. Res. 2007; 14(7):452-462.

[2] Nyanti L, Hii KM, Sow A, Norhadi I, Ling TY. Impacts of Aquaculture at different Depths and Distances from cage culture sited in Batang Ai Hydroelectric Dam Reservoir Sarawak, Malaysia. World Applied Sciences Journal. 2012; 19(4):451-456.

[3] Yee LT, Paka DD, Nyanti L, Ismail N, Emang JJJ. Water Quality at Batang Ai Hydroeletric Reservoir (Sarawak, Malaysia) and Implications for Aquaculture. International Journal of Applied Science and Technology. 2012;

2(6):23-30.

[4] http://dwrm.gov.vn/index.php?language=vi\&nv=news\&op=Tin-thanh-tra/O-nhiem-vi-nuoi-ca-long-be-3878

[5] Ti.com, "AN-1852 Designing with pH Electrodes", 2013

[6] https://luatvietnam.vn/nong-nghiep/quy-chuan-viet-nam-qcvn-02-19-2014-bnnptnt-bo-nong-nghiep-va-phattrien-nong-thon-157372-d3.html\#noidung.

[7] http://sonnptnt.baria-vungtau.gov.vn/web/guest/thong-tin-trong-nganh1/

/brvt/extAssetPublisher/content/5631004/so-nn-ptnt-ban-hanh-huong-dan-tam-thoi-ve-nuoi-ca-long-be-man-lo-trendia-ban-tinh-br-vt.

[8] http://automation.net.vn/Cong-nghe-Ung-dung/Ung-dung-Tu-dong-hoa-va-Cong-nghe-cao-trong-nuoi-trongthuy-san-sieu-tham-canh-ben-vung.html

[9] Tiêu Chuẩn Việt Nam,1995. Các tiêu chuẩn nhà nước Việt Nam về Môi trường. Tập I : Chất lượng môi trường nước. - Trung tâm tiêu chuẩn chất lượng, Hà Nội.

[10] Phạm Mạnh Thắng. Nghiên cứu thiết kế, chế tạo mô đun vào ra dùng trong Tự động hoá được điều khiển qua công nghệ mạng di động GSM. Báo cáo đề tài cấp Đại học Quốc Gia Hà Nội. Mã số QC.07.16 năm 2007.

Ngày nhận bài: 10/01/2020

Ngày chấp nhận đăng: 01/04/2020 